\title{
Estimation of the eddy diffusivity coefficient in a warm monomictic tropical Lake
}

\author{
David A. SALAS DE LEÓN,,$^{1 *}$ Javier ALCOCER, ${ }^{2}$ Vilma ARDILES GLORIA, ${ }^{2}$ Benjamín QUIROZ-MARTÍNEZ ${ }^{3,4}$
}

${ }^{1}$ Instituto de Ciencias del Mar y Limnología, Universidad Nacional Autónoma de México, Av. 3000, Col. Copilco, Del. Coyoacán, 04510 México DF; ${ }^{2}$ Proyecto de Investigación en Limnología Tropical, Universidad Nacional Autónoma de México, FES Iztacala, Av. de Los Barrios No. 1, Los Reyes Iztacala, 54090 Tlalnepantla; ${ }^{3}$ Posgrado en Ciencias del Mar y Limnología, Universidad Nacional Autónoma de México; ${ }^{4}$ Instituto de Biología, Universidad Nacional Autónoma de México, Av. Universidad 3000, Col. Copilco, Del. Coyoacán, 04510 México DF, Mexico

*Corresponding author: dsalas@unam.mx

\begin{abstract}
We used a two-year dataset (1998-1999) of monthly temperature profiles from Lake Alchichica, Mexico to estimate values of the vertical coefficient of eddy diffusivity. This lake is located in a tropical region at high altitude and shows considerable seasonal variations (i.e., rainy and dry seasons). It has an area of $2.3 \mathrm{~km}^{2}$ and a mean depth of $40.9 \mathrm{~m}$. Alchichica is a warm monomictic lake, which annually becomes isothermal near the end of December or early January at the onset of the dry season and remains stratified for the rest of the year (from late March or early April to early December) during the warm-rainy season. Mathematical models of the spatial and temporal variation of passive substances in lakes and oceans require a quantitative formulation of the vertical transport. Vertical mixing is generally a function of the density profile, which, in lakes, can be directly related to the temperature profile. A widely used method to estimate the vertical diffusion coefficients in lakes from temperature data is the flux-gradient method. In the present study, we applied a simple approach to calculate the eddy diffusivity coefficient $\left(\mathrm{K}_{2}\right)$ based on the solution of the vertical component of the modeled temperature equation. We characterized the eddy diffusivity coefficient $\left(\mathrm{K}_{\mathrm{z}}\right)$ in Lake Alchichica as a dynamic coefficient that changes during the year, between years, and with depth, ranging from $10^{-10}$ to $10^{-6} \mathrm{~m}^{2} \mathrm{~s}^{-1}$, whereas typical values of $\mathrm{K}_{\mathrm{z}}$ in thermally stratified lakes range from $10^{-9}$ to $10^{-2} \mathrm{~m}^{2} \mathrm{~s}^{-1}$. As expected, we found the lowest values in the deeper regions of the lake, and that the temporal variation of temperature with depth showed a quasi-bimodal shape from one year to the next. We also found a structure of alternating peaks and troughs in the vertical $\mathrm{K}_{z}$, which indicates a response to oscillating vertical mixing. We concluded that the solution of the vertical component of the temperature equation could be a useful tool to estimate the eddy diffusivity in lakes. The major advantage of this method is its simplicity. We also conclude that the differences observed in the estimations of eddy diffusivity coefficients in other lakes are attributable to the differences in local characteristics of the thermal conditions in each lake.
\end{abstract}

Key words: Eddy diffusivity coefficient; warm monomictic lake; tropical lake; Mexico; Alchichica.

Received: June 2015. Accepted: December 2015.

\section{INTRODUCTION}

Temperature studies in lakes are important in the context of climate change because of the lakes' thermal memory in deep waters (Ambrosetti and Barbanti, 1999). Tropical lakes have smaller seasonal temperature ranges, larger minimal monthly radiation and higher bottom temperatures than temperate lakes (Csanady, 1964). Because higher mean temperatures produce lower density stratification stability, tropical lakes also tend to have small vertical temperature gradients, making the identification of the metalimnion difficult (Powell and Jassby, 1974). In general, tropical lakes both stratify and mix more easily than temperate lakes in response to changes in wind strength and to reversals in the heat flux. Tropical lakes should be viewed as less stable than temperate lakes because of the characteristically high minimum temperatures and the narrow temperature ranges (Lewis, 1996). These characteristics cause any change in stability to be much greater than those in lakes at higher latitudes (Csanady, 1964).
Heat fluxes always occur between two media that have different temperatures, such as when the air temperature differs from the water surface temperature of a lake. As molecular diffusivity is very small compared to eddy diffusivity, in this paper we considered eddy diffusivity, this implies turbulent transport and that molecular processes can be neglected.

This heat flux is proportional to the temperature gradient: a stronger gradient yields a faster heat transfer (Lewis, 1983). The proportionality constant has been measured for the vertical heat flux in lakes and is assumed to be reasonably well known; nevertheless, estimates of the eddy diffusivity coefficient range from $10^{-9}$ to $10^{-2}$ (Powell and Jassby, 1974).

It is customary to estimate diffusion fluxes using Fick's law (Barbante, 2009) assuming that $K_{x}=K_{y}=K_{z}$. Since Alchichica is a stratified lake, we assume that $K_{x, y}$ and $K_{z}$ are different, which means we are not in a Fickian situation. Mathematical models of the spatial and tempo- 
ral variation of passive substances in lakes and oceans require a quantitative formulation of the vertical transport. The McEwen method, although widely used, can lead to inaccurate results (Lewis, 1983; Bartzokas, 1985). For an explanation of the McEwen method see Powell and Jassby (1974). The flux gradient method has been examined and compared to the McEwen method for specific case studies of thermal energy transfers. The lack of agreement between the values obtained by both methods led some investigators to postulate a flux of thermal energy into the deep layers of lakes due to density currents (Bartzokas, 1985). An alternative explanation of this discrepancy is that deep-water turbulent mixing may result from a microstructure of layers and sheets caused, for example, by a Kelvin-Helmholtz shear flow instability or by other instability mechanisms (Lewis, 1987).

Tropical lakes have narrower seasonal temperature ranges and higher minimal monthly radiation and bottom temperatures than temperate lakes. Higher mean temperatures produce lower density stratification stability. Additionally, tropical lakes are more vulnerable to changes resulting from wind and heat than temperate lakes. This is primarily because of the minimal Coriolis effects, low maximum stability, and high response of the stability to changes in heat content (Benoit and Hemond, 1996).

In the present study, we applied a simple approach to calculate the eddy diffusivity coefficient $\left(K_{z}\right)$ based on the solution of the vertical component of the temperature equation; the modelling of the heat transport using $K_{z}$ is an assumption provided from a simplification for coarse grained boxes of the dynamics (Monin and Yaglom, 1971). We use observations taken for two years at regular depths in Lake Alchichica, Mexico. This lake is located in a tropical region at high altitude and shows strong seasonal variations. Therefore, studying a tropical lake such as Alchichica is a challenging task.

\section{Study site}

Alchichica is a volcanic crater lake $\left(19^{\circ} 24^{\prime} \mathrm{N}, 97^{\circ} 24^{\prime}\right.$ $\mathrm{W}$ ) at an altitude of 2,350 $\mathrm{m}$ asl (Fig. 1). It is a deep natural lake (maximum depth of $62 \mathrm{~m}$, mean depth of $41 \mathrm{~m}$ ), with a surface area of $2.3 \mathrm{~km}^{2}$, a maximum length of $1.7 \mathrm{~km}$ and a maximum width of $1.4 \mathrm{~km}$. Its basin holds $94,214,080 \mathrm{~m}^{3}$ of saline $\left(8.5 \pm 0.2 \mathrm{~g} \mathrm{~L}^{-1}\right)$ and alkaline $(\mathrm{pH}=9.0 \pm 0.1)$ water, dominated by sodium-magnesium and chloride-bicarbonate ions (Alcocer and Hammer, 1998; Filonov et al., 2006; Vilaclara et al., 1993). The annual environmental temperature in the region fluctuates from $-5.5^{\circ}$ to $30^{\circ} \mathrm{C}$, with a mean value of $14.4^{\circ} \mathrm{C}$ (García, 1988). This high-altitude plateau is considered a cold desert because of its arid climate, characterized by an annual precipitation regime of less than 500 $\mathrm{mm}$ and an annual evaporation rate of $1690 \mathrm{~mm}$ (Adame et al., 2008). Alchichica is a warm monomictic lake that mixes from late December or early January to late March or early April during the cold-dry season and remains stratified the rest of the year during the warm-rainy season (Adame et al., 2008). For a more detailed description of the general characteristics of Lake Alchichica, see Alcocer et al. (2015).

\section{METHODS}

Monthly temperature profiles spanning a 2-year period (1998-1999) were measured using a Hydrolab DS4 multiparameter water quality data logger and SVR4 logging system. Profiles were taken in the central and deepest parts of the lake (Fig. 1). The thermistor had an operation range from -5 to $50^{\circ} \mathrm{C}$ and an accuracy of $\pm 0.10^{\circ} \mathrm{C}$. Vertical temperature profiles consisted of discrete readings at every meter. Data were visually reviewed and depurated in order to avoid possible electronic or air bubble related noise, averaged monthly to obtain the climatic evolution

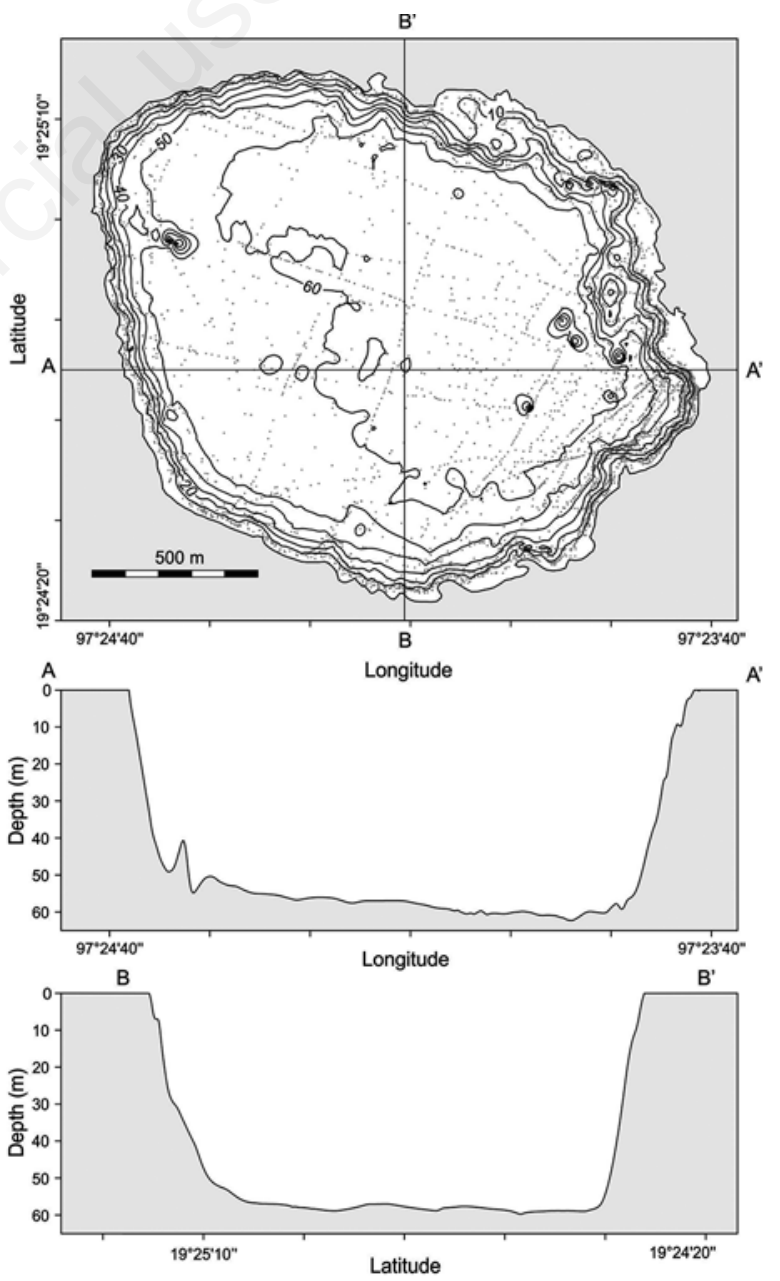

Fig. 1. Bathymetric chart (m) of Lake Alchichica, Mexico. The point at the crossing of AA' and BB' transects indicates the sampling station (gray dots are bathymetry-sampling points). 
of the thermocline of Lake Alchichica during the year (Fig. 2), and plotted versus time and depth (Fig. 3) to identify vertical and temporal structures and evolution.

Vertical mixing is generally a function of the density profile, which, in lakes, is directly related to the temperature profile. A widely used method to estimate vertical diffusion coefficients in lakes from temperature data is the flux-gradient method (Jassby and Powell, 1975). We recognize that the thermal structure in lakes results from the interaction of solar heating and wind stress on the surface of the lake, and we assume horizontal homogeneity. On the other hand, based on hydrophysical measurements and numerical modelling, Filonov et al. (2006) stated that vertical changes in water density are determined by temperature only, Earth's rotation has a negligible influence on lake circulation, and wind stress effects are restricted to the upper layer of the lake, so the advection effects in heat transfer and homogenization are lowered by the heat flux. Thus, according to Chin (2006), the diffusion equation that describes the vertical transport of heat in the water column is:

$$
\frac{\partial T}{\partial t}=\frac{\partial}{\partial z}\left(K_{z} \frac{\partial T}{\partial z}\right)+S_{T}
$$

where $T$ is temperature and $S_{T}$ is a heat source or sink in the water column. Equation (1) is a simplified expression obtained for the large-scale flow and assuming diagonal diffusivity tensor, this expression characterizes the verti-

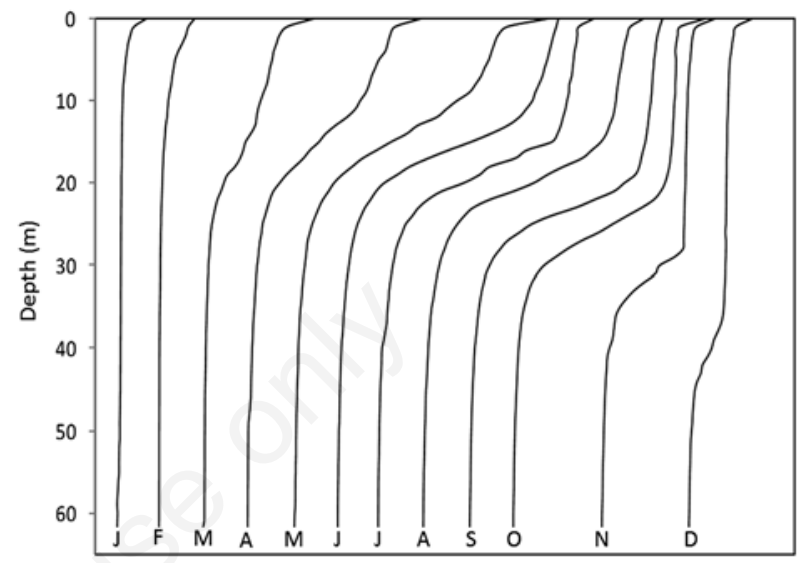

Fig. 2. Consecutive monthly evolution of the average temperature profiles of Lake Alchichica lagged by $1^{\circ} \mathrm{C}$ from one to the next profile during the year.

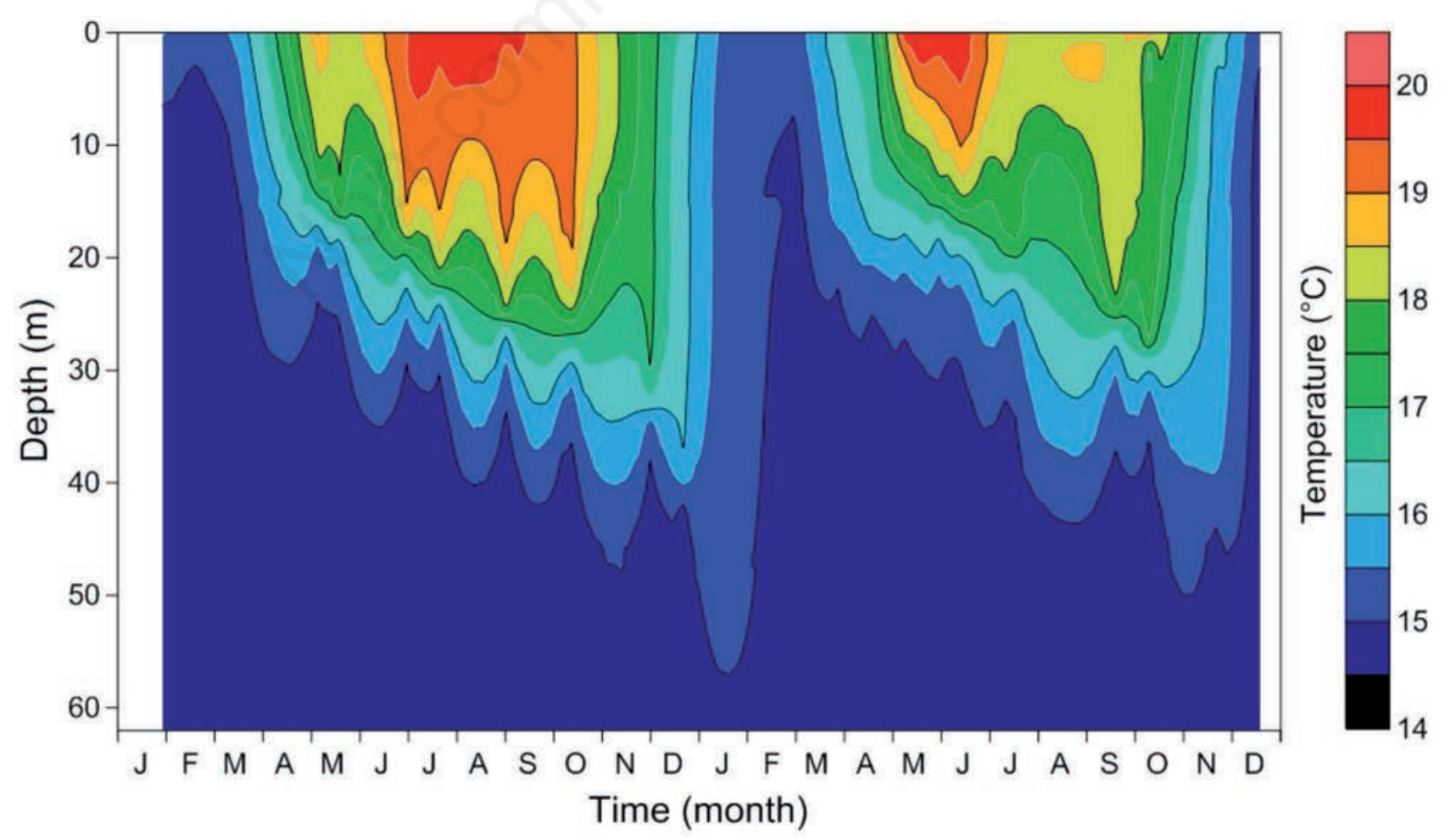

Fig. 3. Depth-Time diagram of isotherms $\left({ }^{\circ} \mathrm{C}\right)$ in Lake Alchichica. 
cal component of the turbulent heat transport, large scale modeled equation. The principal heat source is solar radiation. The first term on the right-hand side of equation (1) represents the vertical diffusion transport of heat, and the diffusion coefficient $K_{z}$ is a function of the thermal structure of the lake. The heat source term, $S_{T}$, can be omitted in the water column except at the surface because light extinction usually limits the penetration of solar radiation into deep water. Integration of equation (1) with respect to $z$ from the bottom of the lake to depth $z$ yields:

$K_{z}=\frac{\int_{-D}^{z} \frac{\partial T}{\partial t} d z}{\frac{\partial T}{\partial z}}$

where the heat flux into the sediments and the radiation absorbed by the sediments at depth $z(=-D)$ are not included. The numerator in equation (2) represents the accumulated rate of change of stored heat between $z$ and the bottom of the lake, and the denominator is the vertical temperature gradient at depth $z$. It should be noted that equation (2) does not apply at the surface because solar radiation at $z=0$ is not included. Accurate temperature readings are essential for a successful application of the flux gradient method, and the numerical solution for this equation is easy. We neglected the heat supplied or lost at the surface because we considered the first surface temperature data in the lake as implicitly containing these fluxes. Some $K_{z}$ calculations result in negative values, due to unstable thin layers (i.e., layers of higher temperature values below colder layers induced by cooling effects that occur mainly in winter). Due to positive or negative $K_{z}$ values imply gain or loss of heat (Gargett, 1984), these results were not taken into account for the $K_{z}$ value calculation because we considered the lake's first surface temperature data imply these fluxes.

\section{RESULTS}

Lake Alchichica has a very regular geometric form (Fig. 1); it is quasi-circular, with straight walls, and shaped like a large cylinder. The average temperature is $15.70^{\circ} \mathrm{C}$, with a maximum of $20.76^{\circ} \mathrm{C}$, a minimum of $14.54^{\circ} \mathrm{C}$, and a standard deviation of $1.45^{\circ} \mathrm{C}$. The monthly variation of temperature throughout the year indicates a deepening of the metalimnion (Fig. 2). In January, the lake is vertically homogeneous; as the year progresses, the atmospheric heating generates a vertical temperature gradient in the surface water. The metalimnion originally close to the surface plunge down to $40 \mathrm{~m}$ in November-December, and virtually disappears in January when the lake circulates; the stratification process restarts in late March or early April. We obtained the vertical temperature profiles shown in Fig. 2 by adding a degree centigrade to each profile. This results in a shift of the profiles from one month to avoid overlap. This allows a better visualization of the evolution of the vertical temperature structure.

Metalimnion subsidence occurs in an oscillating manner in the form of a wave. This is more evident during 1998 (Fig. 3), where we can also see that the oscillations are faster when the metalimnion is more superficial; the period of oscillation in this case is 30 days, whereas when the metalimnion is deeper, the period is 50 days. The temporal variation of temperature with depth shows a quasibimodal shape from one year to the next that is evident in the double peaks of the curve (Fig. 3) for the metalimnion. This could be the result of the midsummer temperatures, which reflect a variation in the environmental temperature induced by early rains formed by evaporation during the early summer. Other interesting aspects are the low-frequency oscillation of the floor of the metalimnion and the tendency of the metalimnion to rise to the surface.

The calculated $K_{z}$ values ranged from $1.17 \times 10^{-10}$ to $2.10 \times 10^{-6}$ (Fig. 4), and as we might expect, we found the lowest values in the deeper regions because $K_{z}$ is proportional to the temperature gradient. However, this does not necessarily occur in the epilimnion, where we found the maximum values of $K_{z}$, as $K_{z}$ also depends on the temporal variation of the temperature gradient. In early 1998, a core of high $K_{z}$ values appeared at a $20 \mathrm{~m}$ depth, which lasted for approximately three months. At the same depth, the $K_{z}$ value was practically zero from the end of March 1998 until early July 1999. In mid-1999, $K_{z}$ increased between 5 and $25 \mathrm{~m}$, with a narrow zone of very low values at 20 $\mathrm{m}$. The high values of $K_{z}$ were interspersed with low values of $K_{z}$ in late 1999. From 30 m deep to the bottom, $K_{z}$ was almost negligible. The structure of alternating peaks and troughs in the vertical $K_{z}$ suggests a response to an oscillating vertical mixing; this process is reflected in the oscillating epilimnion in Fig. 3, where this process is best shown for the $K_{z}$ values in 1998 (Fig. 4). This is consistent with a diffusive physical process.

\section{DISCUSSION}

Typical values of the eddy diffusivity coefficient $\left(K_{z}\right)$ in thermally stratified lakes range from $10^{-9}$ to $10^{-6} \mathrm{~m}^{2} \mathrm{~s}^{-1}$ (Tab. 1). It is noteworthy that different methods to estimate $K_{z}$, result in changes in the order of magnitude of $K_{z}$. The estimation of $K_{z}$ for Lake Alchichica (Fig. 4) shows values ranging from $10^{-10}$ (in circulation) to $10^{-6} \mathrm{~m}^{2} \mathrm{~s}^{-1}$ (in stratification) (Tab. 1, Fig. 4). There is an area of low $K_{z}$ from 35 $\mathrm{m}$ to $55 \mathrm{~m}$, indicating a region of low thermal activity. Below that depth, there are high values of the eddy diffusivity coefficient, which could be an effect of heat transfer with the bottom of the lake (Benoit and Hemond, 1996). Between $5 \mathrm{~m}$ and $20 \mathrm{~m}$, the values of $K_{z}$ are higher. In a se- 
ries of dye experiments in Lakes Huron and Erie, Csanady (1964) found $K_{z}$ values of $7 \times 10^{-4} \mathrm{~m}^{2} \mathrm{~s}^{-1}$ and concluded that the thermocline acts, as in this study, as a diffusion floor. Hutchinson (1957) found values for Sodom Lake, Linsley Pond, and Lake Mendota of $7 \times 10^{-7}, 3.3 \times 10^{-7}$, and $2.5 \times 10^{-6}$ $\mathrm{m}^{2} \mathrm{~s}^{-1}$, respectively; these values are lower than those found in the present study. Lewis (1987) considered that the surface area is much more important than the latitude in controlling the vertical transport of heat through the thermocline; despite the assertion of Lewis, we did not find a strong correlation between surface area, depth or latitude and the eddy diffusivity coefficient (Tab. 1).

The processes transporting heat from the surface to the deep waters in a lake result in a thermal structure, with characteristics varying during the year in both time and depth (Adams et al., 1976; Alvarez-Cobelas et al., 1986). The temporal dynamics of the vertical temperature profiles show major features of the heating process and the effect of wind, reflected in the evolution of the depth of the thermocline. The December profile shows a deep, weak and thin thermocline that is undoubtedly the result of the continued sinking of the cooler and denser surface layers. When the energy provided by the wind is no longer sufficient to overcome the effect of hydrostatic stability, the stratification is maintained. This seems to minimize the mechanism of vertical motion as a method of heat transfer across the thermocline to the hypolimnion. This conclusion seems reasonable because the thermocline represents a definite density discontinuity that eddy currents have to penetrate. The water column in January becomes isothermal, and the lake circulates.

Tropical lakes of moderate to great depth are typically stratified for much of the year. Thus, it is possible that vertical transport across the thermocline in tropical lakes is more pronounced (Lewis, 1982). In Alchichica, the maximum temperature change (surface to bottom) is approximately $4^{\circ} \mathrm{C}$ and occurs during the well-established stratification. The largest temperature changes throughout the metalimnion average $0.94 \pm 0.15^{\circ} \mathrm{C} \mathrm{m}^{-1}$.

Methods previously reported for estimating the eddy diffusivity coefficient from field observations in lakes produce results that differ significantly from one another. The cause of these discrepancies appears to be that each method uses only some of the information contained in the data. Several calculations of the eddy diffusivity coefficient reported in the literature (Tab. 1) provide only one value, yet they use temperature-depth time series data. Powell and Jassby (1974) divided the methods to evaluate $K_{z}$ into three major classes, the first class utilizes a solution of the diffusion equation that we call Method 1 in Tab. 1, the second method ( 2 in Tab. 1) uses the flux gradient, and the third class is based in the McEwen (1929) method. We also add

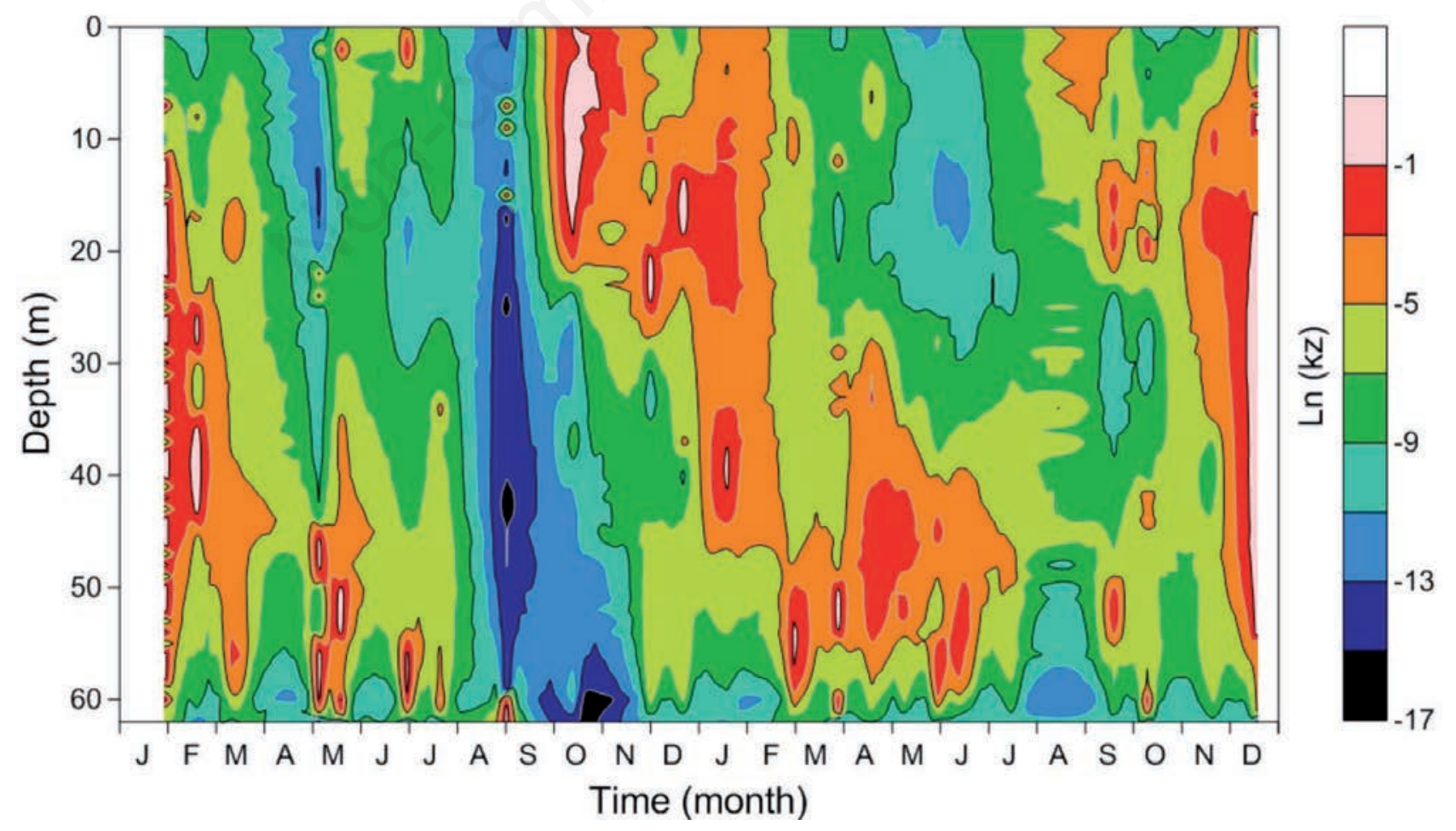

Fig. 4. Natural logarithm of Eddy diffusivity coefficient $\left(K_{z}\right)\left(\mathrm{m}^{2} \mathrm{~s}^{-1}\right)$ estimations for Lake Alchichica, Mexico. 


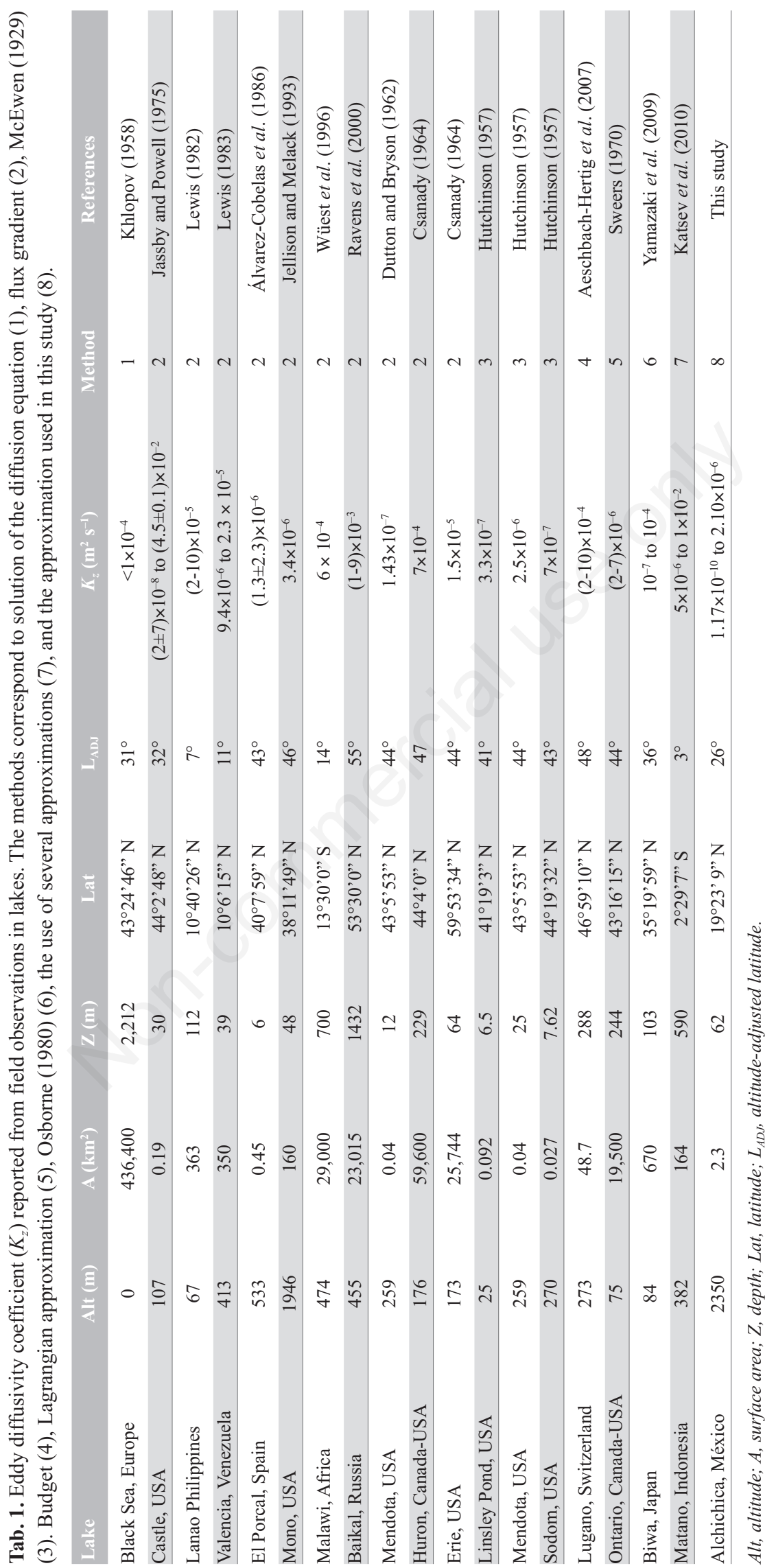




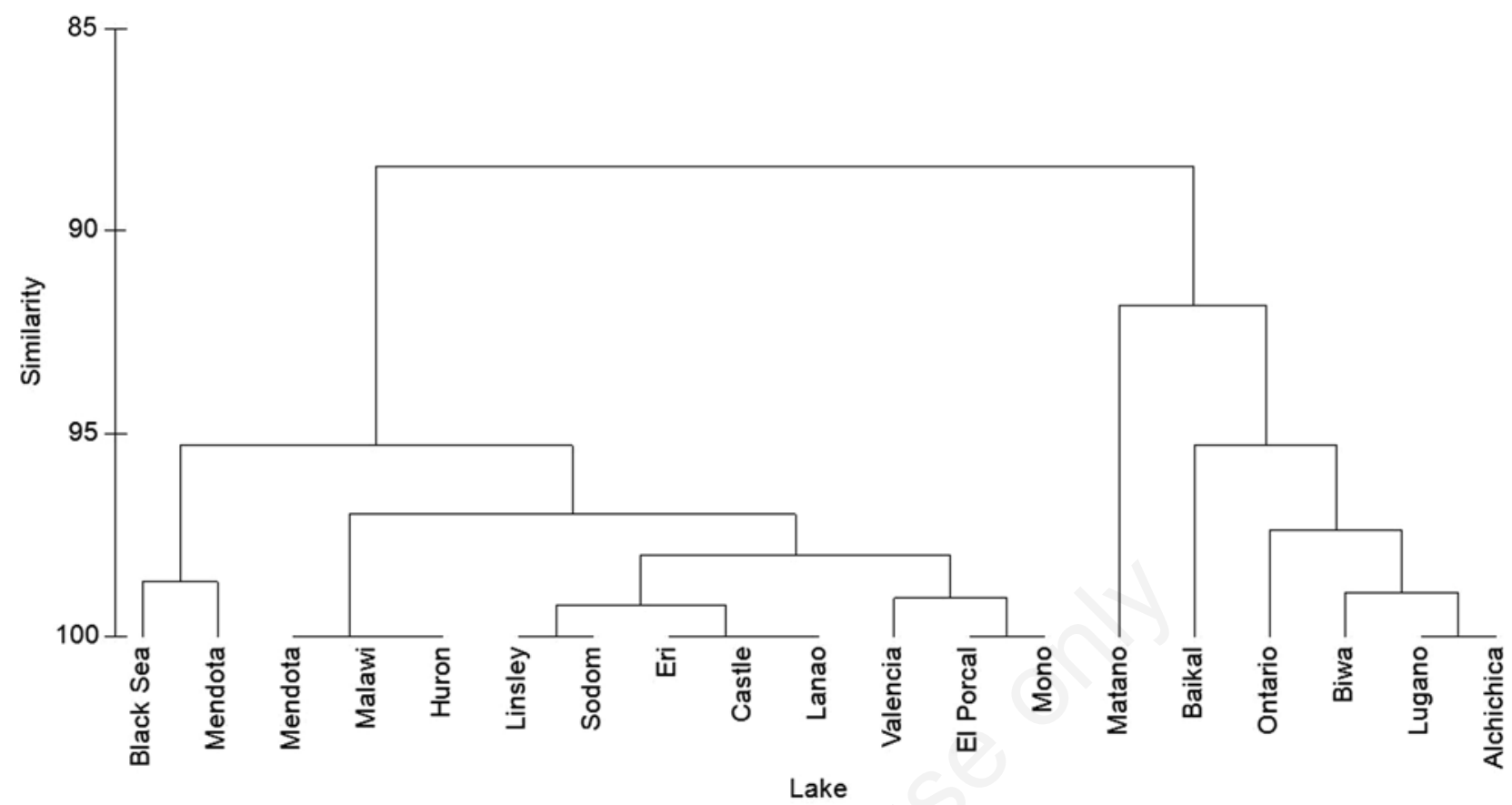

Fig. 5. Dendrogram produced using Bray-Curtis similarity cluster matrix based on double-square-root transformed $K_{z}$ values and method by each lake.

the Budget method (4), the Lagrangian approximation (5), the Osborne (1980) approximation (6), the use of several approximations (7), and the approximation used in this study (8). We performed hierarchical agglomerative clustering on a Bray-Curtis similarity matrix based on doublesquare-root transformed (Clarke, 1993) $K_{z}$ values and on method by each lake in order to find similarities in $K_{z}$ by the used method (Fig. 5). It is interesting to note from figure 5 that the values calculated with the method 2 show results of $K_{z}$ of the order of $10^{-5}$ to $10^{-6}$, calculated with the method 3 are between $10^{-7}$ and $10^{-6}$, while those calculated with methods 4, 5, 6, 7 and 8 presented the greater dispersion in their results. So different methods give different order of magnitude of $K_{z}$ values.

\section{CONCLUSIONS}

The solution of the vertical component of the temperature equation appears to be a useful tool for estimating values of eddy diffusivity in lakes. A major advantage of this method is its simplicity. The eddy diffusivity coefficient in Lake Alchichica is dynamic, with values ranging from $10^{-}$ ${ }^{10}$ to $10^{-6} \mathrm{~m}^{2} \mathrm{~s}^{-1}$; this shows that the existence of a unique value of the eddy diffusivity coefficient for this lake cannot be postulated. The eddy diffusivity coefficient is only a function of the thermal state of the lake. The data considered in this paper suggest that using only one value of $K_{z}$ is not prudent because this could lead to erroneous conclu- sions. The results are sensitive to the model used and reflect the uncertainties and the difficulty of estimating $K_{z}$.

\section{ACKNOWLEDGMENTS}

This project was financially supported by Consejo Nacional de Ciencia y Tecnología (CONACyT) Project 25430-T, Dirección General de Asuntos del Personal Académico de la UNAM (DGAPA) PAPIIT project IN204597, UNAM FES Iztacala project PAPCA 2008 and UNAM ICML project 144 . We are greatly indebted to J. Castro for improving the figures.

\section{REFERENCES}

Aeschbach-Hertig W, Holzner CP, Hofer M, Simona M, Barbieri A, Kipfer R, 2007. A time series of environmental tracer data from deep, meromictic Lake Lugano, Switzerland. Limnol. Oceanogr. 52:257-273.

Adame F, Alcocer J, Escobar E, 2008. Size-fractionated phytoplankton biomass and its implications for the dynamics of an oligotrophic tropical lake. Fresh. Biol. 53:22-31.

Adams WM, Watts G, Mason G, 1976. Estimation of thermal diffusivity from field observations of temperature as a function of time and depth. Amer. Min. 6:560-568.

Alcocer J, Hammer UT, 1998. Saline lake ecosystems of Mexico. Aquat. Ecosyst. Health Manage. 1:291-315.

Alcocer J, Hernández MC, Oseguera LA, Escobar E, 2015. On the ecology of Cletocampus gomezi Suárez-Morales, Barrera-Moreno \& Ciros-Pérez (Crustacea, Copepoda, Harpati- 
coida) micro-endemic to Lake Alchichica, Central Mexico. Limnol. Oceanogr. 74:302-309.

Alvarez-Cobelas M, Rubio A, Acosta FJ, 1986. [Difusión vertical y estabilidad térmica en una laguna hipereutrófica].[Article in Spanish]. Limnética 2:1-9.

Ambrosetti W, Barbanti L, 1999. Deep water warming in lakes: an indicator of climatic change. J. Limnol. 58:1-9.

Barbante PF, 2009. How diffusion modelling affects prediction of heat flux loads (article 76979). In: Proc. 6th European Symp. Aerothermodynamics for Space Vehicles, Versailles, European Space Agency Special Publication Vol. 659.

Bartzokas A, 1985. Estimation of the eddy thermal diffusivity coefficient in water. Arch. Met. Geoph. Biocl. 33:401-405.

Benoit G, Hemond HF, 1996. Vertical eddy diffusion calculated by the flux gradient method: Significance of sediment-water heat exchange. Limnol. Oceanogr. 41:157-168.

Chin DA, 2006. Water-quality engineering in natural systems. J. Wiley \& Sons, Hoboken: 622 pp.

Clarke KR, 1993. Non-parametric multivariate analyses of changes in community structure. Aust. J. Ecol. 18:117-143.

Csanady GT, 1964. Turbulence and diffusion in the Great Lakes. Great Lakes Res. Div. 11:326-339.

Dutton JA, Bryson RA, 1962. Heat flux in Lake Mendota. Limnol. Oceanogr. 7:80-97.

Filonov A, Tereshchenko I, Alcocer J, 2006. Dynamic response to mountain breeze circulation in Alchichica, a crater lake in Mexico. Geophys. Res. Lett. 33:L07404.

García E, 1988. [Modificaciones al sistema de clasificación climática de Köppen (para adaptarlo a las condiciones de la República Mexicana)].[Article in Spanish]. Offset Larios S.A. México D.F.

Gargette AE, 1984. Vertical eddy diffusivity in the ocean interior. J. Mar. Res. 42:359-393.

Hutchinson GE, 1957. A treatise on limnology. Wiley-Interscience New York: 1015 pp.

Jassby A, Powell T, 1975. Vertical patterns of eddy diffusion during stratification in Castle Lake, California. Limnol. Oceanogr. 20:530-543.

Jellison R, Melack JM, 1993. Meromixis in hypersaline Mono Lake, California. 1. Stratification and vertical mixing during the onset, persistence, and breakdown of meromixis. Limnol. Oceanogr. 38:1008-1019.

Katsev S, Crowe SA, Mucci A, Sundby B, Nomosatryo S, Douglas H, Fowle DA, 2010. Mixing and its effects on biogeo- chemistry in the persistently stratified, deep, tropical Lake Matano, Indonesia. Limnol. Ocean. 55:763-776.

Khlopov VV, 1958. The variation of the diffusion coefficient according to Black Sea observations. Bull. Acad. Sci. USSR, Geophys. Ser. 2:129-133.

Lewis WM Jr, 1982. Vertical eddy diffusivities in a large tropical lake. Limnol. Oceanogr. 27:161-163.

Lewis WM Jr, 1983. Temperature, heat, and mixing in Lake Valencia, Venezuela. Limnol. Oceanogr. 28:273-286.

Lewis WM Jr, 1987. Tropical limnology. Annu. Rev. Ecol. Syst. 18:159-184.

Lewis WM Jr, 1996. Tropical lakes: how latitude makes a difference, p. 43-64. In: F. Shiemer and K.T. Boland (eds.), Perspectives in tropical limnology. Academic Publishing, Amsterdam.

McEwen GF, 1929. A mathematical theory of the vertical distribution of temperature and salinity in water under the action of radiation, conduction, evaporation, and mixing due to the resultant convection. Bull. Scripps Inst. Oceanogr. 2:197.

Monin AS, Yaglom AM, 1971. Statistical fluid dynamics. 1. MIT Press, Cambridge: 782 pp.

Osborn T, 1980. Estimates of the local rate of vertical diffusion from dissipation measurements. J. Phys. Oceanogr. 10:83-89.

Powell T, Jassby A, 1974. The estimation of vertical eddy diffusivities below the thermocline in lakes. Water Resour. Res. 10:191-198.

Ravens TM, Kocsis O, West A, Granin N, 2000. Small-scale turbulence and vertical mixing in Lake Baikal. Limnol. Oceanogr. 45:159-173.

Sweers HE, 1970. Vertical diffusivity coefficient in a thermocline. Limnol. Oceanogr. 15:273-280.

Vilaclara G, Chávez M, Lugo A, González H, Gaytán M, 1993. Comparative description of crater-lake basic chemistry in Puebla State, Mexico. Ver. Int. Verein. Limnol. 25:435-440.

Wüest A, Piepke G, Halfman JD, 1996. Combined effects of dissolved solids and temperature on the density stratification of Lake Malawi, p. 183-204. In: T.C. Johnson and E.O. Odada (eds.), The limnology, climatology and paleoclimatology of the East African lakes. Gordon and Breach Scientific Publishers, Amsterdam.

Yamazaki H, Honma H, Nagai T, Doubell M, Amakasu K, Kumagai M, 2009. Multilayer biological structure and mixing in the upper water column of Lake Biwa during summer 2008. Limnology 11:63-70. 